$018-019$

\section{Noticias}

y comentarios

PH43 - Abril 2003

\title{
Páginas de patrimonio y empleo en nuestra web
}

El trabajo desarrollado en los últimos años por el Departamento de Formación y Comunicación del IAPH, nos ha permitido conocer de cerca la situación del mercado de trabajo en el sector del patrimonio y la gestión cultural, y por consiguiente, los problemas que encuentran los titulados en carreras afines al patrimonio para incorporarse por primera vez al mundo laboral. De manera informal y esporádica, como complemento al Programa de Formación, se ha venido ofreciendo información y orientación en materia de empleo a todo aquel que se ha acercado a nosotros solicitando asesoramiento.

Esta experiencia acumulada, unida al trabajo cotidiano en el sector del patrimonio y la gestión cultural, nos ha animado a desarrollar un Proyecto de Información y Orientación Profesional a través de la web, dirigido sobre todo a andaluces titulados universitarios que quieren iniciar su andadura profesional dentro del sector del patrimonio y la gestión cultural.

El proyecto está dividido en dos partes:

1. Información sobre empleo a través de la web del IAPH.

La información colgará del marcador del Departamento de Formación y Comunicación bajo el epigrafe "Patrimonio y empleo" (www.juntadeandalucia.es/ cultura/iaph/formacion/formacion.html), con los siguientes contenidos:

Patrimonio y empleo. Aspectos generales

$>$ Publicaciones e informes sobre las expectativas de empleo en el sector: La valorización del patrimonio y el turismo cultural como Nuevos Yacimientos de Empleo.

$>$ Profesiones tradicionales y nuevos perfiles profesionales.

> Obstáculos para la generación de empleo en el sector.

> Instrumentos necesarios para contrarrestar los obstáculos.

Búsqueda activa de empleo

$>$ Autoconocimiento

> Fuentes de información sobre empleo público y privado

$>$ El currículum

$>$ La carta de presentación

$>$ Autocandidatura

$>$ Entrevistas de selección

$>$ Pruebas psicotécnicas

Formas de acceso al empleo público

$>$ Concurso

$>$ Oposición

$>$ Concurso-oposición

$>$ Bolsas de trabajo

$>$ Contratos administrativos
Formas de acceso al empleo privado

$>$ Tipos de contratos por cuenta ajena

\section{Autoempleo}

$>$ Ventajas e inconvenientes

$>$ Profesional libre

$>$ Empresario: Planteamientos previos, la idea.

El proyecto empresarial. El Plan de Empresa. Formas jurídicas.

> Financiación: Subvenciones, ayudas y otros productos financieros

$>$ Instituciones que ofrecen financiación.

$>$ Convocatorias abiertas de subvenciones y ayudas al autoempleo, actualizadas semanalmente.

Organismos e instituciones publicas y privadas que ofrecen orientación al empleo y autoempleo.

\section{Becas}

> Instituciones que ofertan becas para titulados en carreras que puedan tener alguna vinculación con el patrimonio y la gestión cultural.

> Convocatorias abiertas de becas, actualizadas semanalmente.

Los contenidos tendrán una introducción general seguida de una serie de enlaces con páginas web en los que poder ampliar la información.

2. Información, orientación y asesoramiento vía correo electrónico (orienta.iaph.ccul@juntadeandalucia.es), teléfono (955 037 050) y fax (955 037 050)

Se ofrecerá información, orientación y asesoramiento por estas vías a través de un técnico en orientación laboral del Departamento de Formación y Comunicación que contestará las consultas que nos hagan relacionadas con los contenidos anteriores.

Al ser éste un proyecto en vías de consolidación, sería interesante que nos aportases tu opinión y sugerencias a través del correo electrónico orienta.iaph.ccul@juntadeandalucia.es

Carmen Jorge

Departamento de Formación y Comunicación del IAPH 